\title{
PREVALENCE OF LOW BACK PAIN IN NON WORKING RURAL HOUSEWIVES OF KANPUR, INDIA
}

\section{GARIMA GUPTA and NUPUR NANDINI}

Saaii College of Medical Science and Technology, Kanpur, India

Physiotherapy Department

\begin{abstract}
Objectives: Housewives are nucleus of families but as the working, living, and social architecture in the rural areas significantly differ from developed or urban area, the results of urban population cannot be generalized. Hence the purpose of the present study is to evaluate the prevalence of low back pain in non working rural housewives. Also an attempt has been made to determine the impact of social burden on low back pain (LBP). Material and Methods: A sample of 301 non working rural housewives of Kanpur, aged between 30-70 years was selected. Hindi version of 3 appropriate scales Nordic musculoskeletal questionnaire, Oswestry disability index and Zarit burden interview measuring musculoskeletal discomfort, low back disability and social burden were given to all the housewives. Results: Analysis of data reveals that both recent and yearly prevalence of LBP in rural housewives is $83 \%$. More than $50 \%$ housewives have severe disability due to their LBP. Correlational analysis has shown that there is a significant impact of social burden on their disability due to low back pain. Conclusions: The findings of the present study suggest that $83 \%$ of the non working rural housewives have low back pain and activity restriction due to their pain. They have significant impact of social burden on their low back pain. High prevalence $(83 \%)$ of low back pain among rural housewives is an alarming sign for our society. Better health-care measures to enhance rural housewives education about good posture, ergonomic measures, health schemes, health awareness, and activity pacing could help rural housewives.
\end{abstract}

Key words:

Low back pain, Social burden, Rural housewives, Disability, Prevalence, India

\section{INTRODUCTION}

Low back pain (LBP) is the most frequent work related musculoskeletal complaint and one of the leading causes of health related problems in developed world [1-4]. LBP is a major public health problem in the USA, because more than 34 million (17\%) adults report LBP [5]. On any given day, an estimated 6.5 million people in the United States are bedridden because of back pain and approximately 1.5 million new cases of back pain are seen by physicians in each month [6].

Low back pain is an extremely common human phenomenon, a price mankind has to pay for their upright postures.
The yearly prevalence varies from $5 \%$ to as high as $65 \%$ and lifetime prevalence from $35 \%$ to $80 \%$ [2]. Low back pain is widespread in many countries and is associated with a subgroup developing chronic and disabling symptoms generating large social costs and loss of quality of life as well as taking time off from work [7]. Low back pain is not a life threatening condition, but it constitutes a major public health problem in Western industrialized societies and exhibits epidemic proportions. It affects a large number of people each year and is the cause of great discomfort and economic loss. Recent surveys also indicate that back pain results in restrictions of social and other activities and has

Received: April 19, 2014. Accepted: September 2, 2014.

Corresponding author: G. Gupta, Saaii College of Medical Science and Technology, Physiotherapy Department, 112/283 FFFP Swaroop Nagar, Kanpur, UP, India 208002 (e-mail: gariace@gmail.com). 
substantial impact on the life style of those affected. Low back pain poses an economic burden to society, mainly in terms of the large number of work days lost by a small percentage of patients who develop chronic LBP [8].

Low back pain can affect all age groups and both genders. Most people suffer incapacitating back pain at some stages in their lives. Many people have their 1st episodes of low back pain in their late teens or early twenties and the episode frequently reoccur throughout adult life, leading to a chronic condition [2]. Pain in the soft tissues of the back is extremely common among adults. In the United States, the National Arthritis Data Workgroup reviewed national survey data showing that each year some $15 \%$ of adults report frequent back pain or pain lasting more than 2 weeks. In Canada, Finland and the United States, more people are disabled from working as a result of musculoskeletal disorders (MSDs) - especially back pain - than from any other group of diseases [7]. In India, occurrence of low back pain is also alarming; nearly $60 \%$ of people in India have significant back pain at some time in their lives [6,9].

Epidemiological studies provide important information regarding various risk factors, like age and sex, occupation, life style and socio-economic status, smoking habit. Few studies report that female patients experience more pain than men, the reason may be their more physical activities in workplaces and greater muscular effort [6]. A common finding of previous studies was that the prevalence of pain was higher in women than in men (prevalence of back pain of $24.3 \%$ in women and $20.9 \%$ in men) [10]. On the other hand, few studies suggest that the proportion was higher for men than women, because of higher participation in the labor force and in occupations involving lifting of heavy loads or whole-body vibration [7].

Low back pain receives little attention and research in low-income countries compared to industrialized countries. Many studies have been done in urban areas which show a high prevalence of LBP in housewives [11]. As the working, living, and social architecture in the rural areas significantly differ from urban area, it does not seem reasonable to generalize the results of those studies [4].

Rurality is commonly assumed to represent a barrier to health care access and therefore is expected to result in lower health resource utilization. Compared to urban ones, rural residents were more prone to develop low back pain [12]. Women work every day for about 8-9 h in agriculture and 4-5 $\mathrm{h}$ in household activities; besides, for certain agricultural jobs, females are considered better than males. The daily work schedule of rural women is very demanding and arduous. In addition to agriculture, in an Indian family and in Indian social setup, family members, relatives and neighbours play important roles in one's life. Relationships with those people form a basis for their mental health.

The result is that rural women are overburdened as well as continuously struggling to meet their family and social demands. The household, agriculture and animal care jobs are not only strenuous, but also repetitive. The rural women are exposed to continuous non-neutral postures. The repetitive or prolonged exertion causes pain in the muscles, resulting in muscular weakness or spasms. Long hours of work, continuous attention, precision, job diversity, extreme postures, scanty nutrition and poor health apparently indicate that the farm women, whether tribal or non-tribal, are under serious physical stress [13]. Apart from other medical problems, pregnancy and childbearing aggravate the complications in females [6]. Rural women rarely report their musculoskeletal problems at the right time, "having learned to live with pain" they commonly develop physical disability. Left unaddressed, musculoskeletal disorders can result in lifelong pain and permanent disability.

Thus the purpose of the present study is to evaluate the prevalence of low back pain in non working rural housewives, to determine the impact of social burden on LBP and also to study the effect of age on LBP in non working rural housewives. 


\section{MATERIAL AND METHODS}

This study was an epidemiological survey. The study was approved by research committee of Saaii College of Medical Science and Technology, Kanpur, India. After conducting a survey in the rural block development office, 6 villages from the district Kanpur Nagar (Chaubeypur, Trilokpur, Bhikharipur, Gabhraha, Hridyaypur, Maryani) were selected for the present study. By using quota sampling method, 350 rural women aged 30-70 were interviewed, out of whom 49 were excluded because they did not meet our inclusion criteria. The remaining 301 rural housewives took part in the study (Figure 1).

Like many other studies on prevalence of lower back pain, the present study included only people who were able to read and understand the local language (Hindi) [5,10,14]. Considering the previous literature available, we excluded the housewives who were engaged in any sort of occupational activity other than household work, and also those who were pregnant or diagnosed with diabetes or neurological, cardiovascular or psychiatric disorders [6,15-19]. Housewives with tumor, infection, or any major trauma to the spine causing fracture were also excluded from study [20].

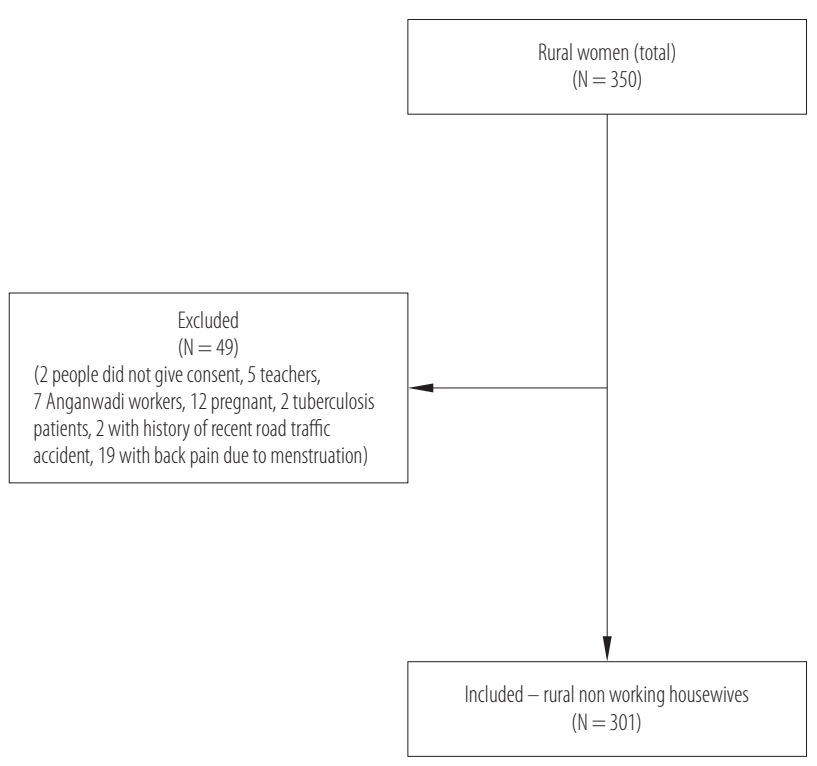

Fig. 1. Subject distribution flow chart
After selecting the villages for the sampling, the interviewer conducted door to door survey in each village. Before proceeding with the interview in each village the interviewer selected at random the location to start the survey. If the women present in the house were eligible according to the inclusion-exclusion criteria and were willing to participate in the study, they were then asked to provide their demographic details, any present or past medical history, family history, surgical history. After explaining the need and purpose of the study, a duly signed written consent was obtained from each woman. All the 3 scales were administered to all of them. In each village the interviewer interviewed 50 respondents; once the sample from one village was complete, then the next village was approached in the same way. In our experience, all the women whom we approached, except 2, were willing to participate in our study.

To answer the research question on the prevalence of low back pain in rural housewives, 3 appropriate scales (Nordic Musculoskeletal Questionnaire - NMQ, Oswestry Disability Index - ODI, and Zarit Burden Interview - ZBI) were selected. Since Hindi is local language used in rural areas of Kanpur, Hindi version of all the 3 scales was used in the present study. NMQ Hindi translation was done using forward and backward translation method. Face and content validity was established for Hindi version of NMQ. User agreements and Hindi version of ODI and ZBI were obtained by signing the user agreement and taking permission from Mapi Research Trust. Housewives were given clear instruction regarding 3 scales used in the present study (NMQ, Zarit Burden Interview, Oswestry Disability Index). The housewives were instructed that they have to fill these scales by themselves; no further assistance was given to them. Data was recorded on the assessment sheets and data collection forms. Analysis of the data was done by using statistical package for social sciences for Windows (SPSS) software (v. 14.0). 


\section{RESULTS}

The study was conducted to find out the prevalence of low back pain in housewives of rural areas of Kanpur. The descriptive statistical analysis of subjects $(\mathrm{N}=301$, rural housewives) shows that the mean age was $41.77 \pm 10.21$.

\section{Prevalence of LBP}

Descriptive analysis of NMQ responses reveals that the prevalence of both recent (in last 7 days) and yearly episodes of low back pain in rural housewives is $83 \%$ (Table 1).

Table 1. Descriptive analysis of Nordic Musculoskeletal Questionnaire (NMQ) showing prevalence of low back pain in rural housewives of Kanpur

\begin{tabular}{lcrc}
\hline \multirow{2}{*}{ NMQ - question } & Response & \multicolumn{2}{c}{ Respondents } \\
\cline { 3 - 4 } & & \multicolumn{1}{c}{$\mathrm{n}$} & $\%$ \\
\hline Low back pain in last 7 days & no & 50 & 16.6 \\
(acute episodes) & yes & 251 & 83.4 \\
Low back pain in & no & 51 & 16.9 \\
$\quad \begin{array}{l}\text { last 12 months } \\
\text { (yearly prevalence) }\end{array}$ & yes & 250 & 83.1 \\
Restriction in daily living & no & 54 & 17.9 \\
activity in last 12 month & yes & 247 & 82.1 \\
\hline
\end{tabular}

\section{Disability due to LBP}

Analysis of data showed that $8 \%$ rural housewives had minimal disability, $22.3 \%$ had moderate disability, $51.5 \%$ had severe disability, $16.6 \%$ rural housewives were crippled and $1.7 \%$ were bed-bound (Figure 2).

\section{Social burden}

Analysis of rural housewives' responses to ZBI showed that $6 \%$ rural housewives were little or no burden, $85.4 \%$ mild to moderate burden while $8.6 \%$ rural housewives represented moderate to severe social burden (Figure 3).

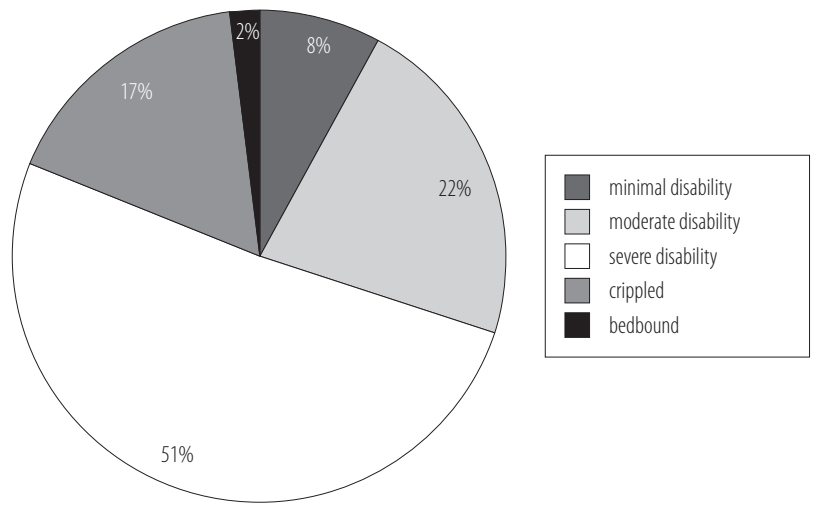

Fig. 2. The prevalence of disability due to low back pain in rural housewives in Kanpur housewives according to Oswestry Disability Index

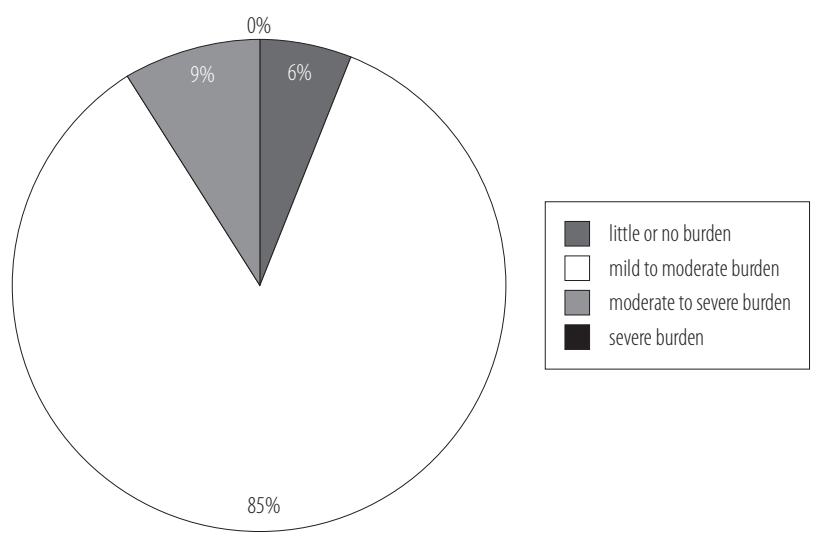

Fig. 3. The prevalence of social burden in rural housewives of Kanpur according to Zarit Burden Interview

\section{Impact of social burden and age on disability} due to low back pain in rural housewives

Pearson correlation analysis showed that social burden and age both have significant impact on disability due to low back pain with $r=0.22$ and 0.42 , respectively ( $\mathrm{p} \leq 0.0001)$.

\section{Prevalence of restriction in activities of daily living} due to low back pain: According to the age group

Cross tabulation analysis showed that in the group of 30-40 year old 172 housewives, 130 reported restriction in activities of daily living due to low back pain; for the remaining studied age groups, the respective values 
were: $41-50$ year old 78 and 70; 51-60 year old 34 and 32; 61-70 year old 17 and 15 (Table 2).

Table 2. Prevalence of restriction in activity of daily living due to low back pain (LBP) based on the Nordic Musculoskeletal Questionnaire (NMQ) according to the age group

\begin{tabular}{lccc}
\hline \multirow{2}{*}{$\begin{array}{c}\text { Age group } \\
\text { (year) }\end{array}$} & \multicolumn{3}{c}{$\begin{array}{c}\text { Respondents } \\
(\mathrm{n})\end{array}$} \\
\cline { 2 - 4 } & without LBP & with LBP & total \\
\hline $30-40$ & 42 & 130 & 172 \\
$41-50$ & 8 & 70 & 78 \\
$51-60$ & 2 & 32 & 34 \\
$61-70$ & 2 & 15 & 17 \\
Total & 54 & 247 & 301 \\
\hline
\end{tabular}

\section{Disability due to low back pain:}

\section{According to the age group}

Statistical cross tabulation analysis showed that 21 out of 172 subjects in the 30-40 year old group were minimally disabled, 51 were moderately disabled, 83 were severely disabled, 17 were crippled; in the 41-50 year old group 1 out of 78 was minimally disabled, 12 were moderately disabled, 46 were severely disabled, 18 were crippled and 1 was bed ridden in the 51-60 group 2 out of 34 subjects were minimally disabled, 3 moderately disabled, 22 severely disabled, 7 were crippled; in the 61-70 group, 1 out of 17 was moderately disabled, 4 were severely disabled, 8 were crippled and 4 was bed ridden (Table 3 ).

\section{Prevalence of social burden: According to the age group}

Statistical analysis showed that in the 30-40 year old group out of 172 subjects 16 fall into the category of little or no burden, 142 into the category of mild to moderate burden, 14 into the category of moderate to severe burden; in the 41-50 year old group out of 78 subjects 2 fall into the category of little or no burden, 68 into the category of mild to moderate burden, 8 moderate to severe burden; in the 51-60 year old group out of 34 subjects, 32 were included into the category of mild to moderate burden, 2 into the category of moderate to severe burden; in the 61-70 year old group out of 17 subjects, 15 were in the category of mild to moderate burden, 2 were in the category of moderate to severe burden (Table 4).

Table 4. Social burden based on the Zarit Burden Interview (ZBI) according to the age group

\begin{tabular}{lcccc}
\hline & \multicolumn{4}{c}{$\begin{array}{c}\text { Respondents } \\
\text { (n) }\end{array}$} \\
\cline { 2 - 5 } $\begin{array}{c}\text { Age group } \\
\text { (year) }\end{array}$ & $\begin{array}{c}\text { little or no } \\
\text { burden }\end{array}$ & $\begin{array}{c}\text { mild to } \\
\text { moderate } \\
\text { burden }\end{array}$ & $\begin{array}{c}\text { moderate } \\
\text { to severe } \\
\text { burden }\end{array}$ & total \\
\hline $30-40$ & 16 & 142 & 14 & 172 \\
$41-50$ & 2 & 68 & 8 & 78 \\
$51-60$ & 0 & 32 & 2 & 34 \\
$61-70$ & 0 & 15 & 2 & 17 \\
Total & 18 & 257 & 26 & 301 \\
\hline
\end{tabular}

Table 3. Disability due to low back pain based on the Oswestry Disability Index (ODI) according to the age group

\begin{tabular}{lcccccc}
\hline \multirow{2}{*}{$\begin{array}{c}\text { Age group } \\
\text { (year) }\end{array}$} & $\begin{array}{c}\text { Respondents } \\
\text { (n) }\end{array}$ \\
\cline { 2 - 7 } & $\begin{array}{c}0-20 \% \text { ODI } \\
\text { (minimal disability) }\end{array}$ & $\begin{array}{c}21-40 \% \text { ODI } \\
\text { (moderate } \\
\text { disability) }\end{array}$ & $\begin{array}{c}41-60 \% \text { ODI } \\
\text { (severe disability) }\end{array}$ & $\begin{array}{c}61-80 \% \text { ODI } \\
\text { (crippled) }\end{array}$ & $\begin{array}{c}81-100 \% \text { ODI } \\
\text { (bed bound) }\end{array}$ & total \\
\hline $30-40$ & 21 & 51 & 83 & 17 & 0 & 172 \\
$41-50$ & 1 & 12 & 46 & 18 & 1 & 78 \\
$51-60$ & 2 & 3 & 22 & 7 & 0 & 34 \\
$61-70$ & 0 & 1 & 4 & 8 & 4 & 17 \\
Total & 24 & 67 & 155 & 50 & 5 & 301 \\
\hline
\end{tabular}




\section{DISCUSSION}

There is extensive literature available on low back pain, but in a developing country like India, less has been documented about the prevalence of low back pain in rural housewives. The findings of the present study show that $83 \%$ of the rural housewives have recent episodes of low back pain. The unique trend found in the present study is that the housewives who have reported recent episodes of pain, have also reported chronic pain and restriction in their daily activities in last 12 months. These observations are consistent with finding of Birabi et al. (2012) that once back pain occurs, it is likely to continue [21]. Similarly, Federico Balague et al. (2012) also found that 10-15\% of the patients with acute pain develop chronic pain and the chronic state represent the great challenge as it does not improve with time and consumes most resources [3].

There are various risk factors which may attribute to housewives' pain, such as recent family conflict (with husband, children or even relatives or neighbors). Most of the housewives during data collection have reported that even though they are not considered to be 'employees' and their working hours are not regulated, they start working early in the morning and continue till midnight. One of the possible reasons for the high prevalence of LBP could be that the combination of farming and other household work is capable of causing low back pain [21]. Their long working hours without sufficient rest periods, poor posture, improper techniques of lifting or carrying loads also contribute to their back pain $[4,9,22]$.

Women are also biologically prone to develop low back pain due to risk factors such as pregnancy, contraceptive use and use of estrogen during menopause. All of these result in hormonal changes responsible for global laxity in the muscles and ligaments of the back, which ultimately leads to dysfunctions of spine $[21,23]$, while post pregnancy weight $[16,17,19]$ or accumulation of more weight around abdomen results in hyperlordosis of lumbar spine and weight line shifts posteriorly and passes through the facet joints. This cause stretching of anterior longitudinal ligament, approaching of pedicles, compression of nerve roots and ultimately causes pain in lower back [6].

The housewives who participated in our study were mainly in the middle age group of 30-40 years. They actively participate in household activities which are common in daily chores of the rural housewives and could be listed as maintaining their home, collecting water, sweeping floor, washing clothes, lifting loads (such as full water containers, bundles of hay), taking care of livestock, preparation of silage, helping their husband in farming. These all activities require repeated bending, twisting movements, lifting and pulling movements of the spine [24]. Koley et al. (2008) reported that manual handling and improper style of lifting objects harm the spine due to abnormal stress and strain imposed on spine during activities [6]. Significant correlation between the disability due to low back pain and social burden $(r=0.22)$ signifies that housewives who had more difficulties at social and family fronts have greater disability due to their low back pain. There is also a positive correlation between disability due to low back pain and increasing age $(r=0.42, \mathrm{p} \leq 0.0001)$. These findings are consistent with findings of Koley et al. and Nikoles et al. who has also reported that prevalence of low back pain rises with age significantly $[6,13]$. Use of quota sampling technique could be the limitation of the research. It is possible that few respondents might have given answers describing pain or disability more than their actual condition. Future studies are recommended to examine availability of health care services and their impact on prevalence of low back pain in rural housewives. Studies on effects of family structure, socio-economic status and educational level of housewives on low back pain and social burden could give us a better understanding of the problem.

The results of the present study would help in determining the impact of low back pain associated with social burden in rural background and also give us epidemiological data regarding 
prevalence of low back pain in rural housewives of Kanpur. High prevalence $(83 \%)$ of low back pain among rural housewives is an alarming sign of our society. Better health care measures to enhance rural housewives education about good posture, ergonomic measures, health schemes, health awareness, and activity pacing could help rural housewives.

\section{CONCLUSIONS}

The findings of the present study suggest that $83 \%$ of the non working rural housewives have low back pain and activity restriction due to their pain. They have significant impact of social burden on their low back pain.

\section{REFERENCES}

1. Pinar ED, Dilek O, Mujde I, Aynur C, Sukran A. Low back pain and related factors in nurses in a university hospital. Turk J Public Health. 2010;8(2):94-104.

2. Hazel J, Chiro M. Classification of low back pain. Australas Chiropr Osteopathy. 2002;10(2):91-7.

3. Balagué F, Mannion AF, Pellisé F, Cedraschi C. Non-specific low back pain. Lancet. 2012;379(9814):482-91, http://dx.doi. org/10.1016/S0140-6736(11)60610-7.

4. Hoy D, Toole MJ, Morgan D, Morgan C. Low back pain in rural Tibet. Lancet. 2003;361(9353):225-6, http://dx.doi. org/10.1016/S0140-6736(03)12254-4.

5. Biglarian A, Seifi B, Bakhshi E, Mohammad K, Rahgozar M, Karimlou M, et al. Low back pain prevalence and associated factors in Iranian population: Findings from the national health survey. Pain Res Treat. 2012;2012:653060, http://dx. doi.org/10.1155/2012/653060.

6. Koley S, Singh G, Sandhu R. Severity of disability in elderly patients with low back pain in Amritsar, Punjab. Anthropol. 2008;10(4):265-8.

7. Punnett L, Prüss-Utün AP, Nelson DI, Fingerhut MA, Leigh J, Tak SW, et al. Estimating the global burden of low back pain attributable to combined occupational exposures. Am J Ind. Med. 2005;48(6):459-69, http://dx.doi.org/10.1002/ ajim.20232.
8. Maniadakis N, Gray A. The economic burden of back pain in the UK. Pain. 2000;84(1):95-103, http://dx.doi.org/ 10.1016/S0304-3959(99)00187-6.

9. Koley S, Sandhu NK. An association of body composition with the menopausal status of patients with low back pain in Tarn Taran, Punjab. India. J Life Sci. 2009;1(2):129-32.

10. Jiménez-Sánchez S, Fernández-de-Las-Peñas $C$, Carrasco-Garrido P, Hernández-Barrera V, Alonso-Blanco C, Palacios-Ceña D, et al. Prevalence of chronic head, neck and low back pain and associated factors in women residing in the Autonomous Region of Madrid (Spain). Gac Sanit. 2012;26(6):534-40, http://dx.doi.org/10.1016/j.gaceta.2011.10.012.

11. Gupta G, Tiwari D. Prevalence of low back pain: Nonworking women in Kanpur City, India. J Musculoskeletal Pain. 2014;22(2):133-8, http://dx.doi.org/10.3109/10582452. 2014.883015 .

12. Joines JD, Taylor DH, Garrett JM, Ricketts TC III, Carey TS. Urban-rural differences in care-seeking for adults with acute severe low back pain. Chapel Hill: The University of North Carolina, Rural Health Research Program, Cecil G. Sheps Center for Health Services Research; 1994 [cited 2014 Mar 15]. Available from: http://www.shepscenter.unc.edu/rural/pubs/report/WP35.pdf.

13. Suthar N, Kaushik V. The impact of physical work exposure on musculoskeletal problems among tribal women of Udaipur district. Int NGO J. 2011;6(2):43-7.

14. Barrero LH, Hsu YH, Terwedow H, Perry MJ, Dennerlein JT, Brain JD, et al. Prevalence and physical determinants of low back pain in a rural Chinese population. Spine. 2006;31(23):2728-34, http://dx.doi.org/10.1097/01. brs.0000244583.35982.ea.

15. Sneag DB, Bendo JA. Pregnancy-related low back pain. Orthopedics. 2007;30(10):839-45.

16. To WW, Wong MW. Factors associated with back pain symptoms in pregnancy and persistence of pain two years after pregnancy. Acta Obstet Gynecol Scand. 2003;82(12): 1086-91, http://dx.doi.org/10.1046/j.1600-0412.2003.00235.x. 
17. Wijnhoven HA, de Vet HC, Smit HA, Picavet HS. Hormonal and reproductive factors are associated with chronic low back pain and upper extremity pain in women - The MORGEN study. Spine. 2006;31(13):1496-502, http://dx.doi. org/10.1097/01.brs.0000220706.96724.76.

18. Ayanniyi O, Sanya AO, Ogunlade SO, Oni-Orisan MO. Prevalence and pattern of back pain among pregnant women attending ante-natal clinics in selected health care facilities. Afr J Biomed Res. 2006;9:149-56.

19. Heude B, Thiébaugeorges O, Goua V, Forhan A, Kaminski M, Foliguet B, et al. Pre-pregnancy body mass index and weight gain during pregnancy: Relations with gestational diabetes and hypertension, and birth outcomes. Matern. Child Health J. 2012 Feb;16(2):355-63, http://dx.doi.org/10.1007/ s10995-011-0741-9.

20. Harvey J, Tanner S. Low back pain in young athletes. A practical approach. Sports Med. 1991;12(6):394-406, http://dx.doi.org/10.2165/00007256-199112060-00005.
21. Birabi BN, Dienye PO, Ndukwu GU. Prevalence of low back pain among peasant farmers in rural community in South South Nigeria. Rural Remote Health. 2012;12:1920. 22. Samad NIA, Abdullah H, Moin S, Tamrin SBM, Hashim Z. Prevalence of low back pain and its risk factors among school teachers. Am J Appl Sci. 2010;7(5):634-9, http:// dx.doi.org/10.3844/ajassp.2010.634.639.

23. Hyder AA, Maman S, Nyoni JE, Khasiani SA, Teoh N, Premji Z, et al. The pervasive triad of food security, gender inequity and women's health: Exploratory research from sub Saharan Africa. Afr Health Sci. 2005;5(4):328-34.

24. Bio F, Sadhra S, Jackson C, Burge P. Low back pain in underground gold miners in Ghana. Ghana Med J. 2007; 41(1):21-5.

This work is available in Open Access model and licensed under a Creative Commons Attribution-NonCommercial 3.0 Poland License - http://creativecommons.org/ licenses/by-nc/3.0/pl/deed.en. 